\title{
MobiQiyas: A Mobile Learning Standardized Test Preparation for Saudi Arabian Students
}

\author{
$\underline{\text { doi:10.3991/ijim.v4i4.1446 }}$
}

\author{
Mohssen M. Alabbadi \\ Computer Research Institute (CRI), King Abdulaziz City for Science and Technology (KACST), Riyadh, Saudi Arabia
}

\begin{abstract}
A mobile learning system, called MobiQiyas, for preparing Saudi Arabian students for one of the standardized tests, given by the National Center for Assessment in Higher Education (NCAHE), has been developed, using ready-made commercial products and tools. The learning material of MobiQiyas consists of practice questions with their answers, both provided by NCAHE, to be loaded by the students into their own mobile phones; after installation, the students can interact with MobiQiyas any number of times, as desired, without incurring any additional cost, other than the initial airtime cost for downloading. From total number of students taken the test, 20,000 students were randomly selected to use MobiQiyas and information was collected from them to measure their attitudes and participation of MobiQiyas. It was found that $36.1 \%$ of students had actually downloaded MobiQiyas successfully. Furthermore, a telephone survey was conducted, after the test period, on a class of $\mathbf{4 0}$ students in a secondary school in Riyadh, taking the same test, to measure their acceptance of MobiQiyas, using a 9-item questionnaire based on a 5-point Likert scale. The responses of the $\mathbf{4 0}$ students reflected high acceptance and satisfaction levels of MobiQiyas as an effective test prep tool.
\end{abstract}

Index Terms-Educational technology, Mobile learning (mLearning), Test preparation (Test Prep), Standardized test, Technology acceptance, User interfaces.

\section{INTRODUCTION}

The lowering cost of mobile devices and the availability of wireless infrastructures have created the "anytime, anywhere, on-the-move" paradigm. The mobile phones market, producing 1.2 billion new mobile phones annually [9], has exceeded the laptop shipment since 2006 [24], where new capabilities in terms of hardware and software are introduced in each new release, with the ability, available only on several models now, to easily acquire and install $3^{\text {rd }}$-party applications. These devices are thus turned into indispensable ubiquitous tools that could replace the desktop and laptops ${ }^{1}$.

This new paradigm offers powerful features and functions such as mobility, reachability, localization, flexibility, information accuracy, and motivational effects and productivity enhancement due to self controlling and better use of spare time. Mobile-based applications are radically transforming the way people communicate, access and utilize information resources, and connect with

The survey, conducted by the Pew Internet \& American Life Project, predicted that most people across the world will be using a mobile device as their primary means for connecting to the Internet by the year $2020^{[5]}$. peers and colleagues. Mobile-based applications were first employed within gaming, movies, or other sectors of the entertainment industry, taking about 12-18 months for their adoption into mainstream industry [7]. They have established a new dimension for providing services such as mobile commerce (mCommerce), mobile business (mBusiness), mobile banking (mBanking), mobile health (mHealth), etc. The Wholesale Applications Community (WAC) ${ }^{2}$ will definitely increase the overall market for mobile-based applications.

There was an impetus to use this new paradigm in the learning environment, thus creating "mobile learning," $\mathrm{m}$ learning or mLearning for short, with expected benefits to be reflected in more efficient and improved learning results. These opening opportunities of mLearning are facing, of course, some challenges and questions. Various issues, particularly user-interface related issues, have been raised, due to weaknesses of the mobile devices such as very small screen displays, low resolution, low processing power, restricted input capabilities of some of these devices, and limited storage capability, thus making the viability of mobile technology in learning questionable. These issues play an important role toward the implementation of mLearning. Therefore, it is critical to study the learner's adoption and acceptance of mLearning for some special application or applications.

Test preparation (i.e., test prep), in particular for standardized tests ${ }^{3}$, is very important learning activity to almost all students. Students all over the world are taking

\section{WAC}

(http://www.wholesaleappcommunity.com/default.aspx), a not-forprofit open global alliance, was created on Feb. 2010, by some of the world's leading telecommunications operators and device manufacturers, fully supported by the GSM Association (GSMA). It aims to establish an open ecosystem to spur the creation of mobile-based applications, regardless of device, operating system (OS), or operator, by encouraging open standardized technologies and providing complimentary commercial models to allow paying the developers for the applications sold through any associated application store.

The earliest record of standardized testing comes from China, taking by applicants for government jobs [6] for the imperial examinations and it was then institutionalized during the $6^{\text {th }}$ century CE, under the Sui Dynasty [22]. On the contrary, examiners in the Western world favored essays, a tradition stemming from the ancient Greeks' affinity for the Socratic methodology [6]. During and after the Industrial Revolution, standardized tests had emerged in the Western world as an easy way to test large numbers of students quickly [6]. By World War I, standardized testing was a common practice in the Western World. Grading of standardized tests was at first done manually, undermining standardized testing's goal of speedy mass assessment, until the IBM 805 Test Scoring Machine, considered to be the first automatic test scanner, was developed in 1938 [8], where electrical current was used to detect marks made by special pencils (e.g., simple No. 2 pencils) on the answer sheets, giving rise to the bubbling-in of answers [6]. 
more standardized tests than ever before, and at ages long before entering colleges. Standardized tests have become one of the largest determining factors in the collegeadmissions process, particularly for élite schools.

A standardized test is a test in which the same test is given in the same manner to all test takers such that its administration and scoring are done in a predetermined consistent manner, thus allowing more reliable comparison of outcomes across all test takers [22]. Standardized tests are often time-limited tests composed of multiplechoice and true-false questions because they can be given and scored inexpensively. However, standardized tests can nearly use any other form of assessment such as essay questions and fill-in-the-blank analogies (e.g., grass:green::sky: $)$, which both require human evaluators. The TOEFL ${ }^{(B)}$ (Test of English as a Foreign Language $^{\mathrm{TM}}$ ) test, provided by the Educational Testing Service (ETS) [http://ets.org/], the $\mathrm{SAT}^{\circledR}$ (Scholastic Aptitude Test $^{\mathrm{TM}}$ ) test, provided by the College Board (http://www.collegeboard.com/), and $\mathrm{ACT}^{\circledR}$ (American College Testing), provided by ACT, Inc. (http://www.act.org/) are some examples of standardized tests. In Saudi Arabia, the National Center for Assessment in Higher Education (NCAHE), subsidiary of the Ministry of Higher Education (MoHE), known as Qiyas ${ }^{4}$, (http://www.qeyas.com/Qiyas/Info/English.aspx), is responsible for preparing, administrating, and giving standardized tests. The tests include 9 educational tests and 3 vocational and licensing tests.

In general, test prep is an activity, where the students normally study in isolation, without the immediate supportive environment, and become aware of nonunderstood aspects or concepts, thus making the students accept the extra charges occurring with mLearning. Furthermore, the mLearning features of motivation and selfpaced learning are fully pronounced in test prep, allowing the students to utilize their spare time effectively.

In this research, a test prep system based on mLearning, called MobiQiyas, is designed and developed, using ready-made commercial products and tools, for one of the standardized tests given Qiyas in Saudi Arabia, on the period of May 7-14, 2009. After MobiQiyas is downloaded and installed into the student's mobile phone, the student can practice solving questions that were given in previous tests of Qiyas, any number of times, as desired by the student, without incurring any additional cost on the student, other than, of course, the initial airtime cost for downloading. For the purpose of this initial trial of MobiQiyas, 20,000 students of the total number of students taking the test were randomly selected to use MobiQiyas. Information was collected from the 20,000 randomly-selected students and another 40 students who belonged to one class of a secondary school in Riyadh for the purpose of measuring their attitudes, participation, and acceptance of MobiQiyas.

The structure of the rest of this paper is as follows. Section 2 defines mLearning and describes its potentials, whereas Section 3 discusses the use of mLearning for test prep, looking at its trends and some of the products available in the market. The description of MobiQiyas is given in Section 4 followed by its trial in Section 5, where the responses of the students, to measure their attitudes, par-

Qiyas is an Arabic word, meaning "measure." ticipation, and acceptance, are analyzed. Finally, the concluding remarks are provided in Section 6.

\section{MOBILE LEARNING}

Mobile learning can be defined as any service or facility for knowledge transfer of events, content, tools, and applications to the learner [4], regardless of location and time [11], resulting in learner's alteration in behaviour [7], where mobile handheld devices (e.g., mobile phones, personal digital assistants (PDAs), and smart phones) are used, while the learner, but not necessarily the learning material providers, could be on the move. The behaviourist requirement indicates that learning is not deemed without the learner's alteration in behaviour [7]. Furthermore, the use mobile handheld devices, possibly on the move, excludes the use of labtops from mLearning [4], thus limiting mLearning to those wireless communication devices that can be used while on-the-move $[10,14]$.

Learning activity is a dynamic activity that can be closely linked to mobility with respect to space, time, and topic areas [21], making a perfect match with mLearning - learning occurs at different places (e.g., learning institutes, workplaces, homes, and even places of leisure), at different times (e.g., working days, weekends, or holidays), and between different topic areas of life (e.g., education, work, self-improvement, or leisure) [21]. The diversity of space for adults' daily self-learning was shown $^{5}$ in [18], thus opening more opportunity for mLearning to support learning during the growing amounts of time that people spend on the move.

Mobile learning is on the intersection of mobile computing and e-learning [13,19], conveying e-learning through mobile devices using wireless connectivity; this intersection includes the use of desktop as well as labtops. It breaks the constraints of time and space, which have become a very important requirement of E-Iearning, thus constructing a flexible and open learning environment. This environmen can provide access, context, and collaboration, and supply additional facilitation measures for facilitators [7].

MLearning actively engages learners, emphasizing learner centeredness to match all learners' styles of learning [14]. From an activity-centered perspective, the six existing learning theories (i.e., behaviourist, constructivist, situated, collaborative, informal and lifelong learning theories) can be harnessed by applying mLearning new practices [15]. Furthermore, the ability to record information about new encountered experiences, using the enhanced features on the mobile devices, enables experiential learning [14]; according to experiential learning theory, ideas and concepts are not fixed, but are formed and modified through the experiences the learners have and by their past experience.

Generally speaking, mLearning systems can be divided into three types: push-based, application-based, or browser-based mLearning systems [12]. The push-based systems use the mobile phone email or Short Message

The daily self-learning episodes for adults took place $51 \%$ at the learner's usual environment (i.e., learner's home or office), $21 \%$ in the workplace outside the office, $14 \%$ in other locations (such as places of worship, the doctor's office, cafes, hobby stores, and cars), $6 \%$ at places of leisure, $5 \%$ outdoors, $2 \%$ in a friend's house, and only $1 \%$ on transport $^{[18]}$. 
Service (SMS), whereas the browser-based systems require an Internet-enabled mobile device, using HTML or wireless application protocol (WAP). Table I gives a comparison of these systems, summarizing their advantages and disadvantages. These systems have been used, either as a single system or as a combination of two or more of them, in some k-12 schools and universities or in career development area, for class learning as well in outdoor learning.

TABLE I.

COMPARISON OF MLEARNING SYSTEMS

\begin{tabular}{|l|l|l|}
\hline \multicolumn{1}{|c|}{ System } & \multicolumn{1}{c|}{ Advantage } & \multicolumn{1}{c|}{ Disadvantage } \\
\hline Push-based & Low cost & $\begin{array}{l}\text { Long interactive time; } \\
\text { Poor and limited con- } \\
\text { tent (for SMS) }\end{array}$ \\
\hline Application- based & Moderate cost & Device Dependent \\
\hline Browser-based & Rich content & High cost \\
\hline
\end{tabular}

The 2009 Horizon Report identified mLearning as one of the emerging technologies, with large impact on teaching, learning, research, or creative expression, to be adopted into the mainstream of learning-focused organizations within the next year (i.e., the first adoption horizon, as defined by Horizon) [9]; Indeed, mLearning was identified at different adaption horizons in the previous two Horizon annual reports [9]. Ambient Insight indicated that the $2^{\text {nd }}$ generation of mLearning will start in 2011, which is characterized as mobile collaboration; the $1^{\text {st }}$ generation, already started in 2007 and to be ended by 2010, includes the three major "native" types of mLearning: locationbased mLearning, device-embedded mLearning, and handheld decision support [4].

Ambient Insight indicated that the US mLearning market reached US\$538 million and US\$632.2million in 2007 and 2009, respectively and it predicts it to continue to grow in the US by a 5-year compound annual growth rate (CAGR) of $18.3 \%$, where revenues will reach US\$1.4 billion by 2014 [1].

\section{STANDARDIZED TEST PREP BASED ON MLEARNING}

As of 2009, the traditional US academic classroombased test preparation industry was a US\$3.1 billion industry, excluding exam preparation revenues related to State-mandated K-12 testing, where the two largest suppliers, accounting for $45 \%$ of all revenues, are the Princeton Review (http://www.princetonreview.com/) and Kaplan (http://www.kaptest.com/), owned by the Washington Post [4]. However, due to decline in revenues, the classroom-based test prep industry is trying to move to technology-based learning products. The market of technology-based learning products, for test prep, compliance assurance, skills assessment, and $\mathrm{NCLB}^{6}$-related testing, is expected to grow by $20-22 \%$, due to consumer, corporate, government, and academic demand [4].

Standardized test prep based on mLearning systems are either push-based or application-based systems; the high cost of browser-based systems makes them unattractive for test prep at the present time. However, the browserbased systems has the advantage of simply implementing

\footnotetext{
6 President George W. Bush's 2001 No Child Left Behind education reform demanded the use of state-mandated standardized testing as a means of assessing school performance ${ }^{[6]}$.
}

adaptability by providing test prep tailored to the learner's ability level, in a similar way as in computerized adaptive testing (CAT). These systems are called computerized adaptive test on mobile devices (CAT-MD) [20]. A prototype of a CAT-MD, using PDAs was designed and developed and evaluated positively by users as well as some experts [20].

An example of push-based mLearning system for standardized test prep is smsPREP (http://smsprep.com/), from smsPREP, Inc. It uses SMSs to supply its US subscribers, for US\$19.99 per month, with practice questions, flashcards, and test-taking strategies, for the PSAT, SAT, ACT tests. The subscriber of smsPREP simply chooses the subject (i.e., math, critical reading, writing, or strategies) and the preferred time, then the correspondence information is sent by SMSs to the subscriber's specified telephone number; for practice questions, the answers and their explanations are sent to the subscriber by SMSs, after the subscriber answers the questions through SMSs.

Furthermore, an SMS-based collaborative mLearning system, called the Dynamic Frequently Asked Questions (DFAQ), was designed and developed at the University of Cape Town (UCT) in South Africa [16], which can be used as a consultation tool during test prep. DFAQ, a seamless web-based application with an SMS interface, allows the students to post questions anonymously, from their own personal study environments, using SMS message, and receive responses, through SMS message from anonymous sources (i.e., peers, educators, and/or tutors) unless otherwise stated. The high increase in the use of the SMS feature of the DFAQ, by almost $200 \%$ as compared during regular class time [16], reflects the need of the students for technology-based test prep tools, thus showing their effectiveness.

The limitations of SMS message on the size ${ }^{7}$ (i.e., 160 characters per message) and the type of information (i.e., only text) make application-based systems the most attractive solution now. There are mobile applications for standardized test prep available in the market that can be simply bought from mobile application stores such as App Store $^{8}$ for the Apple iPhone.

Kaplan Inc. teamed with Jirbo Inc. to release "Kaplan SAT Flashcubes," for iPod Touch and iPhone, including self-study mode and multiple-choice quiz mode, with the capability to track the learner's progress; it is available on the iTunes store (http://itunes.apple.com/app/kaplan-sat flashcubes/id300615175), for US\$4.99, updated on Jan. 30, 2009. The Princeton Review, on the other hand, joined with Modality, Inc. to release, the "GRE Vocab Challenge App" (http://modality.com/apps/GRE-Vocab-Challengeby-The-Princeton Review $p$ 139.html) for iPhone and iPod touch; it can be purchased through, for US\$4.99, through the App Store.

In addition, some standardized test providers are providing mLearning test prep systems. For example, ETS, on December 16, 2008, joined with Nokia to launch English learning courses, designed by ETS teaching and testing experts, for Nokia phone users in China

This has led to conciseness in messages, producing a discursive type of SMS lingo. SMS lingo has become an acceptable SMS language among mobile phone users and there are several SMS lingo dictionaries ${ }^{[23]}$.

In mid-2008, Apple launched the App Store and less than six months later, more than 10,000 such applications were offered. 
http://ets.org/newsroom/news releases/ets nokia learning english. The courses can be downloaded using Nokia's Mobiledu (http://www.mobiledu.cn/en/index.html), where the available courses include TOEFL-type practice questions and TOEIC-type practice questions.

\section{MOBIQIYAS}

MobiQiyas is a mobile learning system for preparing the students for the tests given by Qiyas. It was designed and developed using ready-made commercial products and tools. MobiQiyas provides "anytime, anywhere, and the move" resources with rich interaction for effective learning and performance-based assessment. In addition, it is designed to produce support, motivation, introductions, tips, revision, and study guides. MobiQiyas was motivated by the fact that all students taking the tests of Qiyas own or have access to mobile phones.

Upon receiving an SMS message, sent automatically by a local SMS provider, on the student's mobile phone. The student then simply clicks on the link provided by the SMS to access MobiQiyas as shown in Figure 1. The learning material of MobiQiyas is structured into modules, where each module pertains to one of the tests provided by Qiyas; there could be more than one module related to one single test.

Each module consists of questions, provided by Qiyas along with their answers; the questions were asked in previous tests of Qiyas. The fact that the questions and their answers were provided by Qiyas and the questions were used in previous tests of Qiyas enhances the credibility of MobiQiyas in the eyes of students.

Each module of MobiQiyas is an application based on Java ME (Java Platform, Micro Edition), making it portable across almost all mobile phones as well embedded devices such as personal digital assistants (PDAs), TV settop boxes, etc. It was developed using the Learning Mobile Authoring (LMA) ${ }^{9}$. The LMA enables the creation, customization, review, and update of rich interactive content, containing text, images, audio, and/or video. For MobiQiyas, the content contains neither audio nor video. However, images are used extensively for the inclusion of mathematical equations, special symbols, figures, tables, chemical compounds, etc., providing MobiQiyas with high quality display, thus imitating the real paper-based tests.

The questions are true-false or multiple-choice questions but MobiQiyas has the capability to provide blank filling questions which were never used in Qiyas's tests. For the multiple-choice questions, the correct answers are automatically fed back to the student after two unsuccessful trials; the number of trials is a system variable and could be changed accordingly by the system designer. Each module is equipped with a table of contents and navigational capabilities, using user-friendly icons such as "home," "next," etc.

MobiQiyas has the capability to provide not only the correct answers but also the solutions of the questions and references for further reading. In addition, it can also supply introductory material, review, and study guides.

9 LMA is a free software available from Hot Lava Software, acquired by OutStart in 2009, available at http://www.outstart.com/hotlava-download-registration.htm.
After the student downloads the desired module into his/her mobile phone and the module is installed, the student can then interact with the questions any number of times, as desired, without incurring any additional cost on the student, other than, of course, the initial airtime cost for downloading the desired module.

\section{MOBIQIYAS IN ACTION}

MobiQiyas was launched on 30 April, 2009, lasted until 14 May, 2009, to prepare the students for The General Capabilities Test (GCT), given by Qiyas on the period 714 May, 2009. GCT, containing verbal and quantitative sections, is mandatory for all graduates of secondary schools, before applying for higher education, vocational, or military institutes. For the GCT test, MobiQiyas contained 50 practice questions. Figure 2 shows the table of contents of MobiQiyas of this GCT. In the Appendix, snapshots of some questions for MobiQiyas of this GCT are shown.

For the purpose of this initial trial of MobiQiyas, 20,000 students were selected randomly, across Saudi Arabia, from the total number of students, who were taking this particular GCT test, to measure their responses to MobiQiyas. Furthermore, the Mobile Delivery and Tracking System (MDTS), from Hot Lava Software (acquired by OutStart in 2009), a WAP-based environment, was used to track and record students' responses and for the delivery and management of the GCT test prep module.

Each of the 20,000 randomly selected students received an SMS message, sent automatically by a local SMS provider on 30 April, 2009. The report produced by the SMS
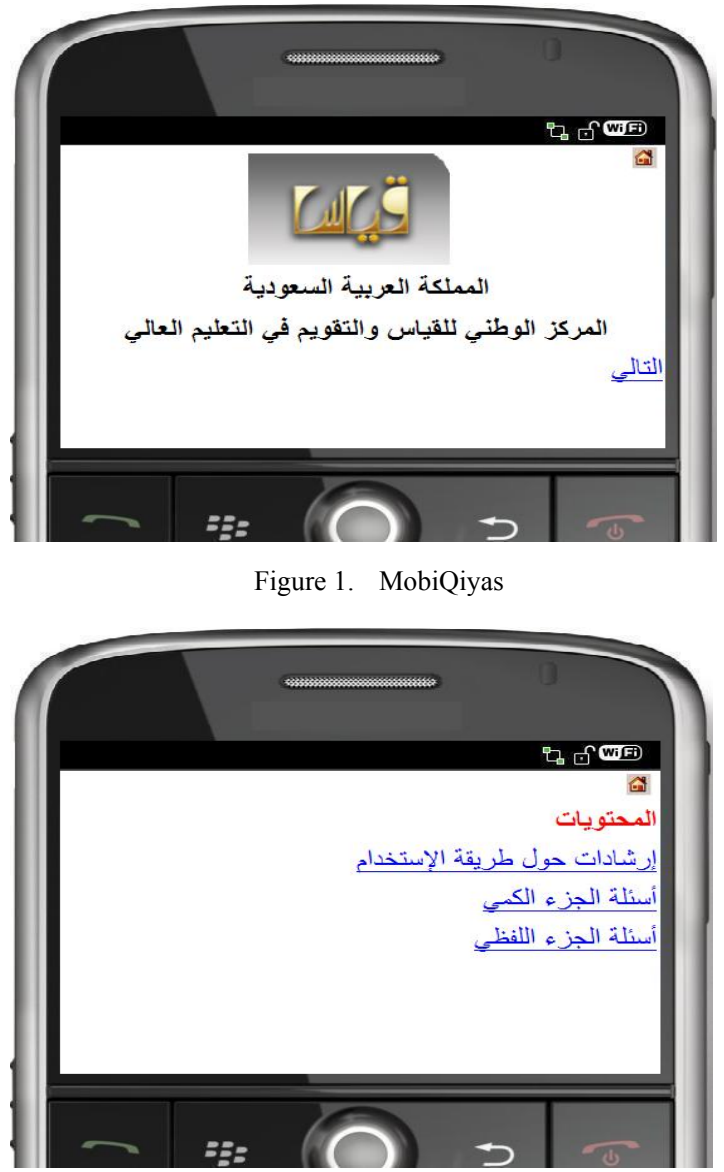

Figure 2. Table of content of MobiQiyas for the GCT test of Qiyas 
provider indicated that the message delivery failure ratio was $2.2 \%$, thus the number of students who actually received the SMS message was 19560. The SMS message, shown in Figure 4, mentioned that the student was selected for the MobiQiyas trial and it further provided information for the student for setting up his/her mobile for Internet connection, as specified by his/her carrier. It also provided information about the cost for downloading the test preparation module; the carrier's airtime-cost was about 1.5 Saudi Riyal (US\$0.40). Furthermore, the SMS message supplies a link to be clicked, if the student desires to download the GCT test prep module.

For the purpose of this initial testing of MobiQiyas, the attitudes, participation, and acceptance of MobiQiyas of the students are measured. The information for the students' attitudes and participation are collected automatically using MDTS; this is can be viewed as the online mode of MobiQiyas, where the students were interacting online with MobiQiyas. On the other hand, the interaction of the students with the questions of module, after downloading and installing the module, can be considered as the offline mode of MobiQiyas. In the offline mode, the student has the freedom to interact with test prep module any number of times, as desired, without incurring any additional cost, other than, of course, the initial airtime cost. The mixing of these two modes reduces the cost incurred on the students. It is to be emphasized that the characteristic of the sample space for this trial (i.e., random selection of students from secondary schools) limits the amount of collected information from the students.

\section{A. Students' attitudes and participation}

A survey was conducted on the students, consisting of two parts. The first part was before downloading the GCT test prep module, which is a questionnaire of two simple questions, whereas the second one was after downloading the test prep module, consisting of only one question. The survey measured the students' attitudes and participation for MobiQiyas. The survey, however, allows the student to skip any of the asked questions by clicking on the "next" link. This option was intentionally chosen to measure students' behavior and their tendencies to participate on surveys.

The responses of the students were tracked and recorded by the MDTS as given in Table II. The first question is about students' readiness, where only $55 \%$ of them indicated that they used the Internet on their mobile phones. It is expected that percentage should be higher than that, considering AdMob Mobile Metrics Report, on July 2009, where Saudi Arabia was ranked $7^{\text {th }}$ in the world, with 151,917,199 downloads of mobile applications [3].

For the downloading of the GCT test prep module, 65\% of the students, who accessed MobiQiyas, indicated that they successfully downloaded the module. On the other hand, accessing MobiQiyas and the download of the module were automatically tracked and recorded by the MDTS, as depicted in Figure 4.

As shown in Figure 5, the number of students who actually accessed MobiQiyas is 7060 students. They all had downloaded the GCT test prep successfully, representing $7060 / 19560=36.1 \%$ of the students who actually received the SMS message.

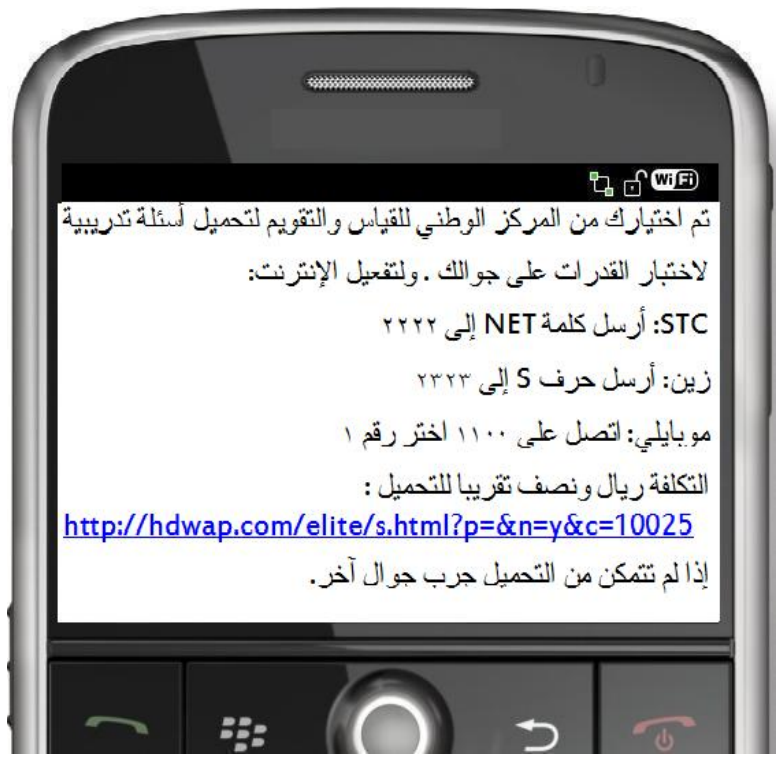

Figure 3. The SMS message sent to the 20,000 randomly selected students

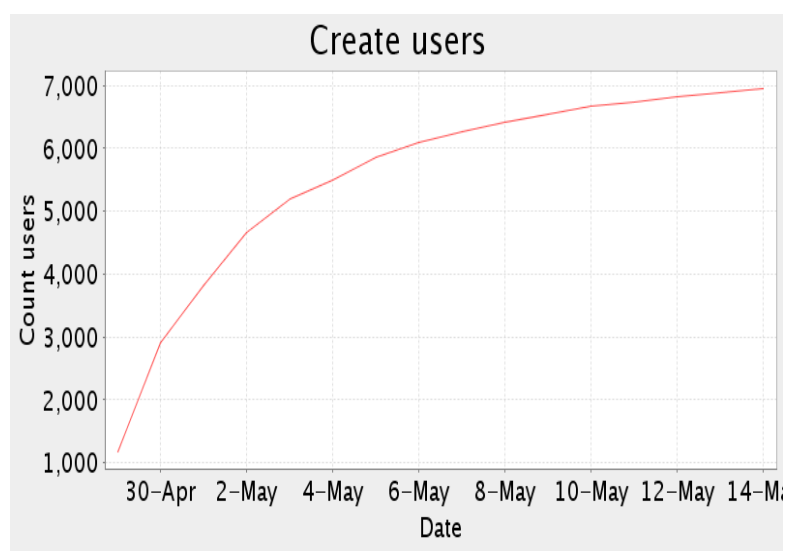

Figure 4. The number of students who accessed MobiQiyas and downloaded the GCT test prep successfully as recorded automatically by the MDTS.

TABLE II.

RESPONSES OF STUDENTS

\begin{tabular}{|c|l|c|c|c|}
\hline & \multicolumn{1}{|c|}{ Question } & Yes & No & Skipped \\
\hline 1 & $\begin{array}{l}\text { Have you ever accessed the } \\
\text { Internet through your mobile } \\
\text { phone? }\end{array}$ & $55 \%$ & $40 \%$ & $5 \%$ \\
\hline 2 & $\begin{array}{l}\text { Do you want to download the } \\
\text { test prep module? }\end{array}$ & $94 \%$ & $6 \%$ \\
\hline 3 & $\begin{array}{l}\text { Did you download the test } \\
\text { prep module successfully? }\end{array}$ & $65 \%$ & $31 \%$ & $4 \%$ \\
\hline
\end{tabular}

Examining the students' responses to the $3^{\text {rd }}$ question in Table II and Figure 4 shows a major discrepancy. This could be attributed to students' confusion between downloading and installation, even though there was a message after the download, indicating that the download was successful.

Clearly, the data in Table II reflects, in general, the tendency of the students, in particular high school students, to participate non-positively in surveys, in non-controlled environment. This may be attributed to students' fear of consequences, making the students to skip the questions and giving inaccurate responses. This suggests using an- 
other method to measure students' acceptance of MobiQiyas. Students' acceptance should be measured in a controlled environment.

\section{B. Students' Acceptance}

After the period of the test was over, another survey was conducted on a class of 40 students belonging to one class of a secondary school in the city of Riyadh, where the students had taken the same test as the 20,000 randomly selected students; fortunately, the students of this class were not part of the 20,000 randomly selected students. This is a telephone survey performed by one of the 40 students. The telephone was used to conduct the survey because most of the students were in vacation and telephone was the best way to reach them. Furthermore, using telephone provides a level of seriousness, which is mostly needed for this particular age of the students.

For this trial, Shackel's usability model [17] is one of the most suitable methods to measure the acceptance of learners, since it considers usability to be an aspect that influences product acceptance. With this model, for a system to be usable, it has to achieve defined levels on the following four constructs: effectiveness, learnability, flexibility, and attitude [17]. The nature of this survey prevents us from using lengthy questionnaire, as was done in [2].

A 9-item questionnaire was designed, where the questions, to some extent, can be mapped to the questions in [2]. The survey is based on a 5-point Likert scale, ranging from "Strongly Disagree" to "Strongly Agree." The response that indicates the lowest approval (i.e., "Strongly Disagree") received a score of 1 , with an increase of 1 point for each response (i.e., 2 points for "Disagree," 3 points for "Neutral," 4 points for "Agree,") until the response that indicates the greatest approval (i.e., "Strongly Agree") received a score of 5. This instrument has thus maximum score of is $5 * 9=45$ and minimum score is 9 . Data gathered on this questionnaire were coded in SPSS for analysis purposes. The responses of the students to the questionnaires are summarized in Table III.

TABLE III.

TYPE SIZES FOR CAMERA-READY PAPERS

\begin{tabular}{|c|l|c|c|}
\hline \multicolumn{1}{|c|}{ Question } & Mean & $\begin{array}{c}\text { Standard } \\
\text { Deviation }\end{array}$ \\
\hline 1 & $\begin{array}{l}\text { Practicing MobiQiyas was very } \\
\text { enjoyable. }\end{array}$ & 4.38 & .91 \\
\hline 2 & $\begin{array}{l}\text { I think all my friends who used } \\
\text { MobiQiyas are happy about it. }\end{array}$ & 4.13 & .87 \\
\hline 3 & $\begin{array}{l}\text { I would like to use a similar system } \\
\text { for other test preparation. }\end{array}$ & 4.20 & .92 \\
\hline 4 & $\begin{array}{l}\text { Practicing MobiQiyas was effec- } \\
\text { tive. }\end{array}$ & 4.20 & .73 \\
\hline 5 & $\begin{array}{l}\text { Practicing Using MobiQiyas has } \\
\text { motivated me. }\end{array}$ & 4.37 & .92 \\
\hline 6 & $\begin{array}{l}\text { MobiQiyas made me better use my } \\
\text { leisure time. }\end{array}$ & 4.33 & .88 \\
\hline 7 & $\begin{array}{l}\text { MobiQiyas helped me to learn new } \\
\text { words. }\end{array}$ & 4.31 & .82 \\
\hline 8 & $\begin{array}{l}\text { MobiQiyas helped me to learn new } \\
\text { concepts. }\end{array}$ & 3.11 & 1.82 \\
\hline 9 & $\begin{array}{l}\text { MobiQiyas helped me to correct } \\
\text { some misunderstood concepts. }\end{array}$ & 4.10 & .81 \\
\hline Scoring: 5 = Strongly Agree, 1 = Strongly Disagree & \multicolumn{2}{|c|}{} \\
\hline
\end{tabular}

As it is clearly shown in the table, the students' acceptance of MobiQiyas is very high, where most responses score more than 4, implying "Agree" response. There was only one question with a score of 3.11 , regarding whether the student learned new concepts from MobiQiyas. This score is very reasonable, considering that MobiQiyas in this trial only supplies practice questions. In general, the students' responses reflect high acceptance and satisfaction levels for MobiQiyas as a test preparation tool. Furthermore, the students expressed their desires to have more questions and their willingness to pay for the incurred charges.

\section{Students' Comments}

After launching MobiQiyas on April 30, 2009, a press was released by Qiyas in most major newspapers in Saudi Arabia, describing the service. The comment sections, related to the press release, of these newspapers, were monitored. Most of the comments came from students who were not randomly selected by Qiyas, showing interest to be part of the trial. Indeed, some of them asked to publish the link; this shows the readiness of the students to use MobiQiyas. One interested comment stated that "this is the real meaning for eLearning." On the contrary, there were some negative feedbacks, concerning only the cost of MobiQiyas.

\section{CONCLUSION}

The mLearning-based test prep, called MobiQiyas, for preparing students for one of the standardized tests given by Qiyas in Saudi Arabia, provides learning material, consisting of practice questions with their answers. MobiQiyas is to be loaded to the student's mobile phones and after installation, the students can interact with it any number of times, as desired by the student, without incurring any additional cost, other than the initial airtime cost for download. MobiQiyas was put into action with 20,000 students, selected randomly from the total students taken the test, where $36.1 \%$ of students had actually accessed and downloaded it. After the test period, a telephone survey was conducted on only 40 students to measure their acceptance of MobiQiyas using a 9-item questionnaire based on a 5-point Likert scale, ranging from "Strongly Disagree" to "Strongly Agree." The responses from those 40 students reflect high acceptance and satisfaction levels of MobiQiyas as a test preparation tool.

\section{ACKNOWLEDGMENT}

The author would like to thank the National Center for Assessment in Higher Education (NCAHE) for providing the questions and their answers. In addition, special thanks are due to Mr. Mohammed Alabbadi for conducting the telephone survey and Mr. Hasan Alabbadi for his help in generating the learning material of MobiQiyas.

\section{REFERENCES}

[1] S. S. Adkins, "The state of mobile learning industry," mLearnCon: The Premier mLearning Conference \& Expo, June 15-17, 2010, San Diego, USA (Presentation of the key findings of the Ambient Insight's report, "The US Market for Mobile Learning Products and Services: 2009-2014 Forecast and Analysis," Monroe, WA, USA: Ambient Insight, LLC; Retrieved on Sep. 9, 2010, from the following URL: http://www.ambientinsight.com/Resources/Documents/AmbientInsight-Mobile-Learning-Market-2009-2014.pdf). 
[2] AdMob, "AdMob Mobile Metrics Report", July 2009 (Retrieved on Sep. 9, 2010, from URL:http://metrics.admob.com/wpcontent/uploads/2009/08/AdMob-Mobile-Metrics-July-09.pdf)

[3] M. M. Alabbadi, "Learners' acceptance based on Shackell's usability model for supplementary mobile learning of an English course, "In the Proceedings of the $2^{\text {nd }}$ International Conference on Computer Supported Education (CSEDU2010), April 7-10, 2010, Valencia, Spain.

[4] Ambient Insight, "Ambient Insight's 2009 Learning and Performance Technology Research Taxonomy," Monroe, WA, USA: Ambient Insight, LLC, September 2009 (updated) (Retrieved on Sep. 9, 2010, from URL: http://www.ambientinsight.com/Resources/Documents/AmbientIn sight_Learning_Technology_Taxonomy.pdf).

[5] J. Anderson and L. Rainie, "The Future of the Internet III," Pew/Internet: Pew Internet \& American Life Project, Washington, DC, USA: Pew Internet \& American Life Project, Dec. 14, 2008 (Retrieved on Sep. 9, 2010, at URL: http://www.pewinternet.org/ /media//Files/Reports/2008/PIP_Fut ureInternet3.pdf.pdf).

[6] D. Fletcher, "Standardized testing," TIME, Dec. 11, 2009. Retrieved online, on Sep. 9, 2010, at the following URL: http://www.time.com/time/nation/article/0,8599,1947019,00.html.

[7] S. J. Geddes, "Mobile learning in the $21^{\text {st }}$ century: Benefit for learners," Knowledge Tree E-journal, Edition 6, 2004 (Retrieved on Sep. 9, 2010, from the following URL: http://knowledgetree.flexiblelearning.net.au/edition $06 /$ download/G eddes.pdf).

[8] IBM Archives, Exhibits, IBM Special Products (Vol. 1), "The IBM 805 test scoring machine," New York, NY, USA: IBM Corporation (Retrieved on Sep. 9, 2010, at the following URL: http://www03.ibm.com/ibm/history/exhibits/specialprod1/specialp rod1 9.html)

[9] L. Johnson, A. Levine, and R. Smith, "The 2009 Horizon Report," Austin, Texas, USA: The New Media Consortium (NMC), 2009 (joint collaboration between NMC and the EDUCAUSE Learning Initiative (ELI), an EDUCAUSE Program; Retrieved on Sep. 9, 2010, at URL http://www.nmc.org/pdf/2009-Horizon-Report.pdf).

[10] D. Keegan, “ The incorporation of mobile learning into mainstream education and training," In the 4th World Conference on mLearning (mLearn 2005), Cape Town, South Africa, October 25282005 (Retrieved on Sep. 9, 2010, at URL: http://www.mlearn.org.za/CD/papers/keegan1.pdf).

[11] F. Lehner, H. Nösekabel, and Lehmann H. "Wireless E-learning and communication environment: WELCOME at the University of Regensburg," In The Proceedings of the First International Workshop on M-Services - Concepts, Approaches, and Tools (ISMIS'02), Lyon, France, June 26, 2002, CEUR-WS.org, CEUR Workshop Proceedings, Vol-61, Z. Maamar, W. Mansoor, and W. van den Heuvel, Eds. (Retrieved on Sep. 9, 2010, at URL: http://ftp.informatik.rwth-aachen.de/Publications/CEUR-WS/Vol61/paper2.pdf).

[12] Y. Li, H. Guo, G. Gao, R. Huang, and X. Cheng, "Ubiquitous elearning System for Dynamic Mini-courseware Assembling and Delivering to Mobile Terminals," In the Proceedings of the Fifth International Joint Conference on INC, IMS, and IDC (NCM 2009), August 25-27, 2009, Seoul, Korea, J. Kim, D. Delen, Park J., F. Ko, C. Rui, J. H. Lee, W. Jian, and G. Kou, Eds. Los Alamitos, CA, USA: IEEE Computer Society's Conference Publishing Services (CPS), 2009, pp. 1081-1086

[13] M. Milrad, "Mobile learning: Challenges, perspectives, and reality," Mobile Learning Essays on Philosophy, Psychology and Education, K. Nyiri, Ed. Vienna: Passagan Verlag, 2003, pp. 151164.

[14] P. B. Muyinda, E. Mugisa, and K. Lynch, "M-Learning: The educational use of mobile communication devices," In the Proceedings of the 3th Annual International Conference On Computing and ICT Research (SREC 07), Volume III, J. M. Kizza, J. Muhirwe, J. Aisbett, K. Getao, V. W. Mbarika, D. Patel, A. J. Rodri- gues, Editors, Kampala, Uganda, August 5-8, 2007, pp. 290-301, Fountain Publishers: Kampala, Uganda, 2007 (Retrieved on Sep. 9,2010 , at URL:

http://cit.mak.ac.ug/iccir/downloads/SREC 07/Paul\%20Birevu\%2 OMuyinda $\% 20, \% 20$ Ezra $\% 20$ Mugisa $\% 20, \% 20$ Kathy $\% 20$ Lynch 0 7.pdf).

[15] L. Naismith, P. Lonsdale, G. Vavoula, and M. Sharples, "Literature review in mobile technologies and learning," NESTA Futurelab Series, Report 11, NESTA Futurelab: Bristol, UK, 2004. (Retrieved on Sep. 9, 2010 at URL:

http://elearning.typepad.com/thelearnedman/mobile learning/repo rts/futurelab review 11.pdf; also available at URL:

http://www.futurelab.org.uk/resources/documents/lit_reviews//Mo bile Review.pdf.).

[16] D. Ng'ambi and A. Knaggs, "Using mobile phones for exam preparation," In the Proceedings of the IADIS International Mobile Learning Conference, Algarve, Portugal. 11-13 April. 2008, pp. $35-42$.

[17] B. Shackel, "Usability - Context, Framework, Design and Evaluation," In B Shackel, B. and Richardson, S. (Eds.), Human Factors for Informatics Usability, Cambridge, UK: Cambridge University Press, 1991, pp. 21-38.

[18] M. Sharples, J. Taylor, and G. Vavoula, "Towards a theory of mobile learning," In the Proceedings of the $4^{\text {th }}$ World Conference on Mobile Learning (mLearn 2005), 25-28 October 2005, Cape Town, South Africa (Retrieved on Sep. 9, 2010, at URL: http://www.mlearn.org.za/CD/papers/Sharples\%20Theory\%20of\% 20Mobile.pdf).

[19] A. Stone, Designing "Scalable, effective mobile learning for multiple technologies," In Learning with Mobile Devices, J. Attwell and C. Savill-Smith, Eds. London, UK.: Learning and Skills Development Agency, 2004.

[20] E. Triantafillou, E. Georgiadou, and A. A. Economides, "The design and evaluation of a computerized adaptive test on mobile devices," Computers \& Education, Volume 50, Issue 4, May 2008, pp. 1319-1330 (Available online, as of Sep. 08, 2010, at www.sciencedirect.com).

[21] G. N. Vavoula and , M. Sharples, "KLeOS: A personal, mobile, knowledge and learning organisation system," In the Proceedings of the IEEE International Workshop on Wireless and Mobile Technologies in Education (WMTE 2002), August 29-30, 2002, Växjö, Sweden, M. Milrad and U. H. Kinshuk, Eds. Los Alamitos, CA, USA: The IEEE, Inc., 2002, pp. 152-156.

[22] Wikipedia, the free encyclopedia, "Standardized test," Aug. 17, 2010, Wikipedia ${ }^{\circledR}$, Wikimedia Foundation, Inc (Retrieved on Sep. 9, 2010, at URL: http://en.wikipedia.org/wiki/Standardized test).

[23] Wikipedia, the free encyclopedia, "SMS language," Aug. 27, 2010, Wikipedia ${ }^{\circledR}$, Wikimedia Foundation, Inc (Retrieved on Sep. 9, 2010, at URL: http://en.wikipedia.org/wiki/SMS_language).

[24] N. Wingfield, "Time to leave the laptop behind," The Wall Street Journal, Feb. 23, 2009, page R1 (Retrieved on Sep. 9, 2010, at: http://online.wsj.com/article/SB122477763884262815.html).

\section{AUTHOR}

M. M. Alabbadi is with the Computer Research Institute (CRI) at King Abdulaziz City for Science and Technology (KACST), P. O. Box 6086, Riyadh - 11442, Saudi Arabia (e-mail: alabbadi@kacst.edu.sa). His research interests include mobile learning, wireless sensors networks (WSN), ubiquitous computing, cryptography, and information security.

This work was supported in part by Elite Network, a Saudi-based company.

Submitted, September 10, 2010. Published as resubmitted by the authors on September 27, 2010 . 
MobiQiyas: A Mobile Learning Standardized Test Preparation for SAUdi ARABian StUdents

APPENDIX: SNAPSHOTS OF SOME OF THE QUESTIONS OF MOBIQIYAS FOR THE GCT TEST OF QIYAS
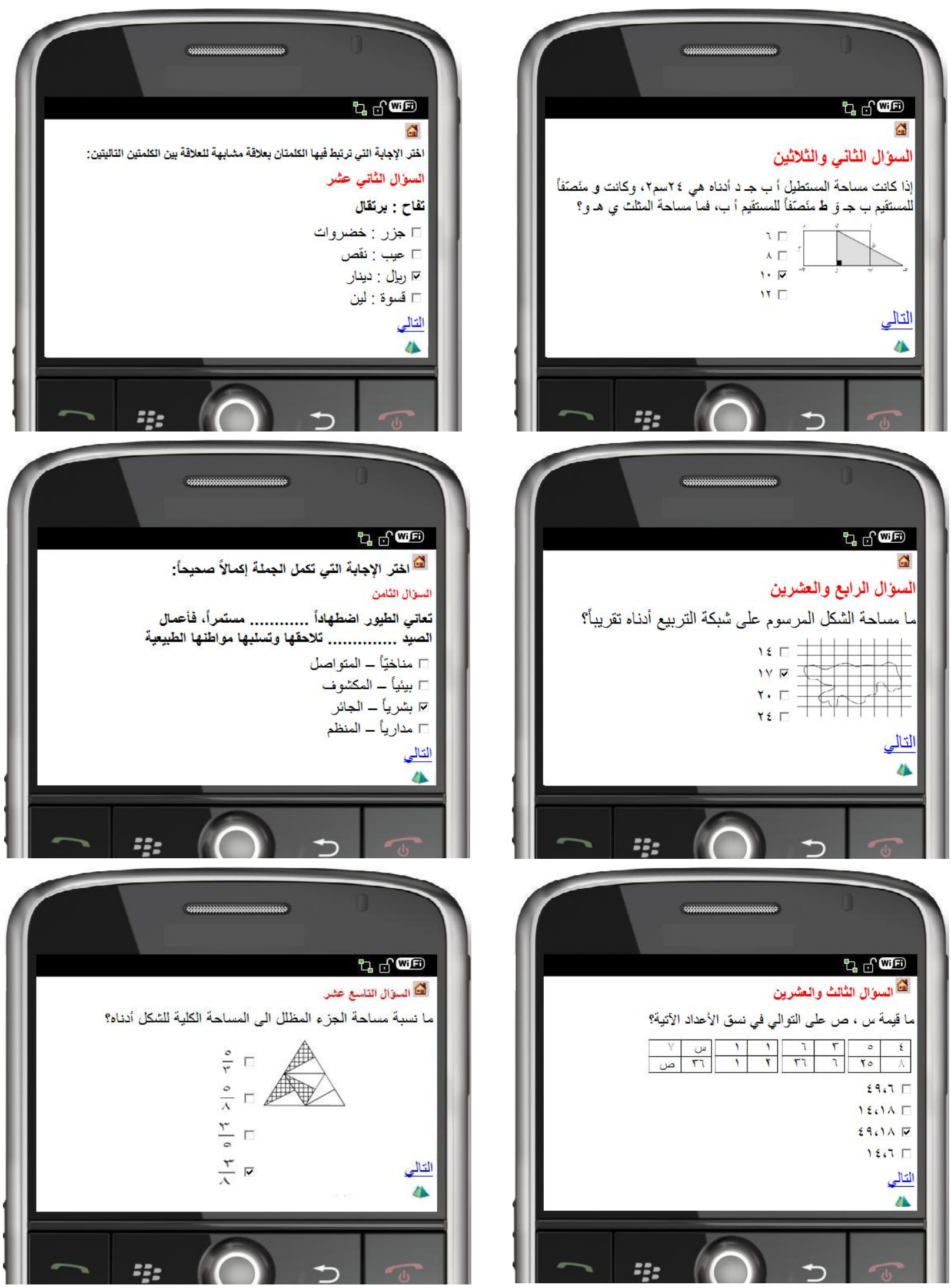